\title{
Leitura argumentativa na escola: propostas didáticas fundadas na perspectiva interacional da argumentação
}

Argumentative reading in school: teaching proposals based on the interactional perspective of argumentation

\author{
Isabel Cristina Michelan de Azevedo* \\ icmazevedo2@gmail.com \\ http://orcid.org/0000-0002-5293-0168
}

\author{
Louriane Ribeiro Reis ${ }^{* *}$ (D) \\ lourianereis@yahoo.com.br \\ https://orcid.org/0000-0003-2653-1734
}

\author{
Nadija Santos Monte ${ }^{* * *}$ (D) \\ nadijamonte@outlook.com \\ https://orcid.org/0000-0002-6776-2478
}

\section{Resumo}

A leitura argumentativa é um campo que, atualmente, ainda carece de estudos específicos no Brasil e no mundo. Neste artigo, pretende-se discutir como esse tipo de leitura pode ser concebida e concretizada em classes de língua portuguesa no ensino fundamental, tematizando-a nos âmbitos teórico e prático com base em duas pesquisas realizadas no Mestrado Profissional em Letras/UFS, campus São Cristóvão. Metodologicamente, as pesquisas exploratórias e intervencionistas realizadas entre 2018 e 2019, por duas professoras-pesquisadoras, foram combinadas a fim de indicar como a leitura em perspectiva interacional pode ser articulada ao modelo dialogal da argumentação com vistas a promover práticas de leitura de textos marcados pela argumentação. Os resultados permitiram compor seis princípios orientadores para o desenvolvimento da leitura argumentativa na educação básica.

Palavras-chave: Compreensão leitora; Argumentação; Modelo dialogal; Ensino-aprendizagem.

\footnotetext{
* Universidade Federal de Sergipe (UFS), São Cristóvão, SE, Brasil.

** Universidade Federal de Sergipe (UFS), São Cristóvão, SE, Brasil.

${ }^{* * *}$ Universidade Federal de Sergipe (UFS), São Cristóvão, SE, Brasil.
}

\section{LINHA DÁGUA}




\begin{abstract}
Argumentative reading is a field that still lacks specific studies in Brazil and abroad. This article aims at discussing how this reading type can be conceived and realized in Portuguese language classes in Elementary School, both in a theoretical and practical scope, based on two professional master's level studies in Languages/UFS (Federal University of Sergipe), São Cristóvão campus. Methodologically, these exploratory and interventionist studies, carried out between 2018 and 2019 by two teachers/researchers, were combined in order to indicate how reading in an interactional perspective can be articulated with the dialogue model of argumentation envisioning the promotion of reading practices for argumentative texts. The results enabled us to establish six guiding principles for the development of argumentative reading in basic education.
\end{abstract}

Keywords: Reading Comprehension; Argumentation; Dialogue Model; Teaching.

\title{
Introdução
}

O interesse pelo ensino da argumentação na educação básica tem proporcionado incursões em campos diversificados de pesquisa. Se, por um lado, esse esforço exige rigor conceitual relativo às noções que são mobilizadas em diferentes áreas científicas ou em variados contextos de estudo da argumentação, por outro, também requer a investigação de práticas escolares que possibilitem o exercício da leitura e da produção da argumentação pelos sujeitos envolvidos em processos de ensino-aprendizagem.

Diferentes trabalhos mostram que o ensino da argumentação na escola tem se limitado ao ensino da redação dissertativa direcionada ao sucesso dos estudantes em exames vestibulares ou de larga escala (VIDON, 2018; AZEVEDO, 2015; LIMA; PIRIS, 2017, entre outros) e que os livros didáticos restringem a abordagem da argumentação aos operadores argumentativos, a outros elementos que favorecem a coesão textual e à tipologia dissertativa-argumentativa (VIDON, 2013, SOUZA; PIRIS, 2018), o que pouco tem contribuído para o desenvolvimento das competências argumentativas na educação básica tanto no que se refere às práticas de leitura quanto de produção de texto.

Como essa temática permite a assunção de diferentes perspectivas teórico-analíticas, neste artigo, resolvemos refletir acerca do ensino da leitura argumentativa, por observarmos a carência de materiais que possam subsidiar as práticas dos professores em atuação na educação básica, sobretudo os que estão interessados em trabalhar em perspectiva interacional, uma vez que a literatura acadêmica, não apenas em português, tem privilegiado as preocupações em torno da escrita de textos argumentativos. Agregamos a essa constatação o fato de, ao longo de vários anos de docência como professoras de língua portuguesa na educação básica, notarmos uma grande dificuldade por parte dos estudantes na leitura de materiais marcados pela argumentação, principalmente pelo fato de demonstrarem não compreender como as ideias são articuladas em exemplares de gêneros preponderantemente argumentativos em circulação na sociedade brasileira.

\section{LINHA DÁGUA}


Tais problemas indicam que o desenvolvimento do letramento na escola continua sendo algo necessário - visto que a argumentação está presente nas práticas sociais de leitura e escrita - e desafiador - posto que assumir posicionamentos e defender ou contrapor ideias, por exemplo, são capacidades que precisam ser aprendidas, sobretudo em uma sociedade letrada. Como reconhecemos que é responsabilidade social da escola formar sujeitos com condições para participar ativamente de situações sociais de uso da linguagem, resolvemos dedicar atenção especificamente à leitura argumentativa no ensino fundamental.

Por assumirmos que, no ensino de língua portuguesa, a linguagem está em posição central, porque é uma atividade social, histórica e cultural que promove relações sociais entre os sujeitos em diálogo, resolvemos nos empenhar em tratar o processo de argumentação em classe como uma prática social e dialógica que possibilita ampliar conhecimentos linguísticos, pragmáticos e interacionais (PLANTIN, 2008a). De um ponto de vista procedimental entendemos que a leitura argumentativa requer a mobilização de procedimentos singulares, como, no caso de uma argumentação oral, ouvir e interpretar o discurso do outro que interage conosco, para que seja possível identificar “[...] o assunto que nele está em questão, a perspectiva veiculada pela forma de o tematizar e o modo como são reforçadas, sob a figura do fundamento ou das garantias, as respostas por ele apresentadas" (GRÁCIO, 2010, p. 357).

Esse entendimento também favoreceu encontrar alternativas para atender às exigências educacionais encontradas na Base Nacional Comum Curricular, doravante BNCC, que na competência geral número sete recomenda que os professores de língua portuguesa organizem propostas didáticas que permitam aos estudantes: "Argumentar com base em fatos, dados e informações confiáveis, para formular, negociar e defender ideias, pontos de vista e decisões comuns [...]" (BRASIL, 2018, p. 9). Como podemos constatar, nesse documento federal, a argumentação em sala de aula tem um papel estratégico nas ações educacionais.

A exiguidade de referenciais teóricos é acompanhada pela falta de materiais didáticos destinados a subsidiar as práticas docentes, o que nos motivou a propor práticas pedagógicas relacionadas à leitura argumentativa a fim de que os estudantes aprendam a ler e posicionar-se como sujeitos discursivos. Para tanto, com base em pesquisas intervencionistas realizadas no Profletras $^{1}$, vinculada à Universidade Federal de Sergipe, campus São Cristóvão, foi possível organizar propostas didático-pedagógicas, experimentadas em duas escolas públicas localizadas em dois estados distintos (Bahia e Sergipe). Tais pesquisas partiram da análise dos gêneros que circulam na esfera pública, incluindo os que pertencem ao campo jornalísticomidiático, a fim de articular informações, opiniões, materiais linguísticos, discursivos e semióticos, para que os estudantes pudessem compreender o processo da argumentação e da persuasão.

1 O Profletras é um curso de pós-graduação stricto sensu (mestrado), desenvolvido em rede, em universidades localizadas em todas as regiões do país, subsidiado pela Coordenação de Aperfeiçoamento de Pessoal de Nível Superior (CAPES), fundação vinculada ao Ministério da Educação (MEC) do Brasil.

\section{LINHA DÁGUA}


$\mathrm{Na}$ sequência deste texto, passaremos a discutir essas experiências; por isso, organizamos esta escrita em quatro partes após esta introdução: (1) apresentamos as referências teóricas quanto à leitura e à argumentação, que fundamentaram as propostas didáticas; em seguida, (2) encontra-se o percurso teórico/metodológico utilizado para o desenvolvimento do trabalho, bem como os resultados alcançados com as turmas de ensino fundamental (anos finais) que participaram da pesquisa; após a análise dos dados reunidos em duas pesquisas intervencionistas, (3) realizamos uma síntese que visa a sistematizar o trabalho com a leitura argumentativa, antes de (4) reunir as considerações finais deste artigo.

\section{Bases discursivas e interacionais para o desenvolvimento da leitura argumentativa}

Para favorecer o entendimento de como as referências teóricas foram mobilizadas na composição das atividades que integram as propostas didáticas que serão apresentadas a seguir, subdividimos esta seção em duas partes. Na primeira, demarcamos a concepção de leitura argumentativa adotada neste artigo e, na segunda, apresentamos, de maneira sucinta, as concepções centrais do modelo dialogal, proposto por Christian Plantin, principal referência consultada ao longo das ações empreendidas em duas escolas públicas entre 2018 e 2019.

\subsection{0 conceito de leitura argumentativa}

O conceito de leitura argumentativa está apoiado na visão de que realizamos variadas práticas de leitura em sociedade que solicitam dos sujeitos compreender as posições enunciativas, os argumentos construídos por meio de diferentes recursos (lógicos, linguísticos, semióticos etc.), por exemplo, depreendidos por meio da compreensão dos discursos.

Nesse sentido, a leitura argumentativa está associada aos usos da leitura em diferentes situações comunicativas. Estas são determinadas, entre outros fatores, pelo momento histórico, pelas relações sociais, pelas experiências dos participantes, pelas características das instituições às quais os sujeitos se encontram vinculados, pela proximidade ou pelo distanciamento entre os interlocutores e como isso pode ser registrado na língua, pelo objetivo da atividade de leitura. Por isso, trata-se de um tipo de leitura considerado em perspectiva interacional. Trata-se de uma prática complexa que requer, então, a mobilização de uma multiplicidade de recursos linguístico-discursivos, cognitivos, sociais que determinam os diferentes modos de ler (KLEIMAN, 2004).

Embora os professores reconheçam a importância da leitura argumentativa, como também da escrita, por vezes hesitam em introduzir um trabalho específico em sala de aula, visto que se estabelece um debate de ideias, por vezes, com viés combativo e até competitivo (NEWELL et al., 2011). Além disso, assumimos que, para ser possível realizar a leitura argumentativa, o estudante precisa compreender um texto desde o processamento do material

\section{LINHA DÁGUA}


gráfico verbal, passando pela decodificação de sílabas, palavras, sintagmas, a fim de conseguir construir significações e estabelecer sentidos para a escrita.

Com isso, reconhecemos que a leitura argumentativa requer do leitor o processamento das palavras e sentenças contidas no texto (nível linguístico) e a análise semântica dos elementos combinados nas informações encontradas no material impresso (nível textual) como base, para que possa efetivar outros processos e, consequentemente, compreender um texto:

- a organização das representações dos significados, isto é, raciocinar de maneira analítica acerca do que foi identificado (nível cognitivo);

- a análise do modelo situacional (nível comunicativo);

- a construção de inferências a partir das posições depreendidas da compreensão do texto, considerando os valores axiológicos em circulação em sociedade ou assumidos pelo sujeito (nível discursivo), tal como se vê sintetizado na Figura 1 a seguir.

Figura 1. Componentes da compreensão da leitura

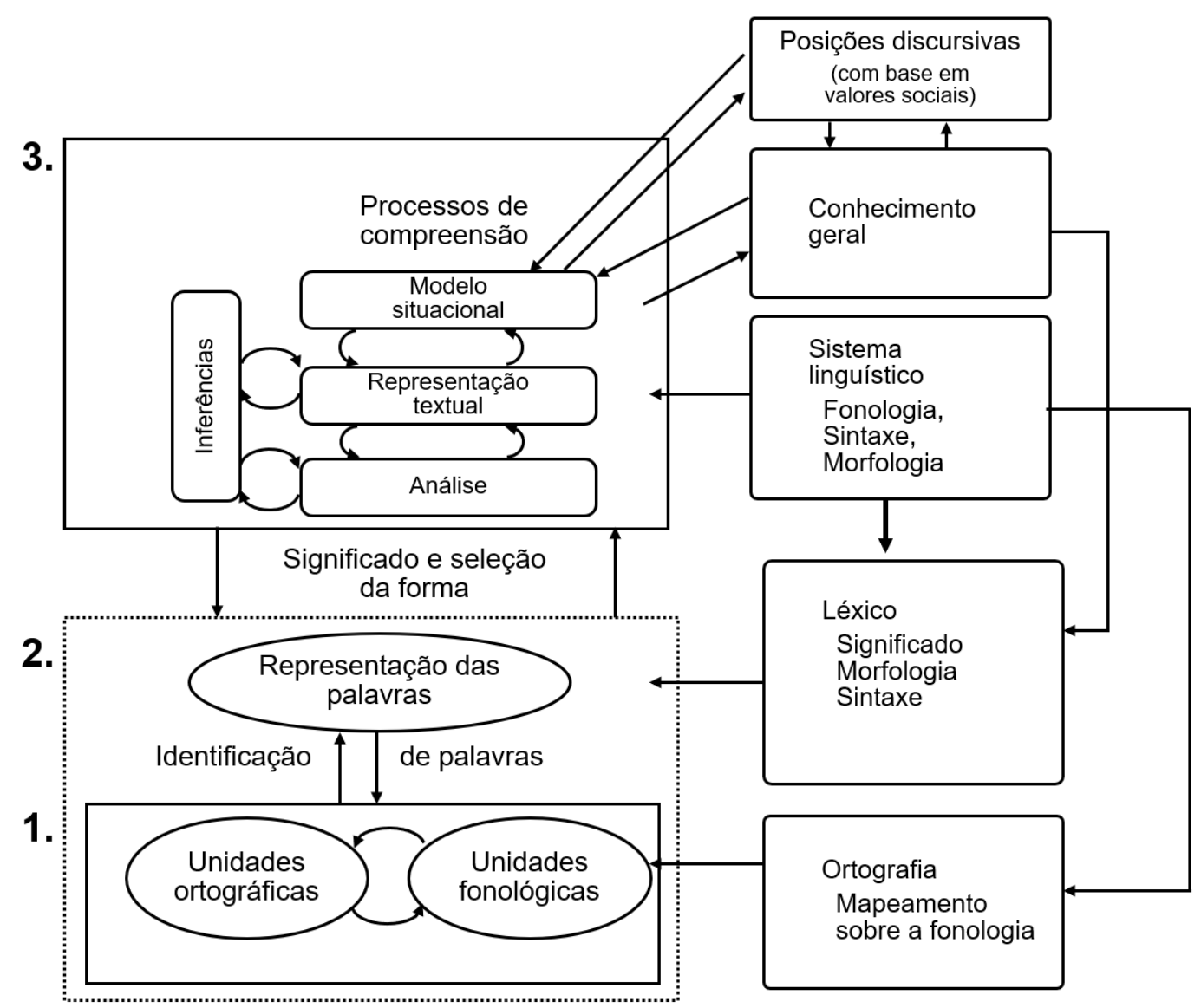

Fonte: Adaptado pelas autoras de Perfetti, Landi e Oakhill (2013, p. 247).

\section{LINHA DÁGUA}


Nesse esquema, percebemos que há dois blocos de processamento que se interrelacionam: na base está um tipo de processamento que inclui a identificação de palavras (1) e a representação semântica delas (2), ou seja, realizar um tipo de processamento que não é exclusivamente linguístico, pois está vinculado a outras fontes de conhecimento. Em função disso, a facilidade de decodificação das palavras e a recuperação de seus significados serão relevantes no trabalho com a leitura argumentativa.

A partir dessa base - que inclui conhecimentos de todos os níveis linguísticos, as condições do leitor para lidar com os fatores superiores na compreensão (3) e a construção de inferências de vários tipos -, ocorre o monitoramento da compreensão, bem como a observação da coerência entre as representações do leitor ao longo da leitura, que pode ser confirmada ou não. Desse modo, torna-se necessário, por vezes, realizar reparos ou ajustes, sensíveis aos aspectos histórico-sociais que estão implicados nas características do gênero discursivo, abrangendo os recortes temáticos, a construção composicional e o estilo de cada um. O leitor ainda terá que articular os valores axiológicos que constituem o modo como interpreta o mundo e os que estão representados na materialidade do texto.

Confirma-se, assim, que os conhecimentos de ordem textual associam-se aos linguísticos, para que a compreensão discursiva associada à argumentativa possa ser efetivamente empreendida. Vemos, então, que o processo de leitura, sobretudo aquele voltado à análise de textos marcados pela argumentação, requer um tratamento interdisciplinar, visto que exige tanto a descrição do processo interativo e transacional ${ }^{2}$ quanto uma análise das relações estabelecidas entre os sujeitos em práticas sociais de uso da linguagem (LEFFA, 1999). Trata-se, portanto, de assumir a leitura como uma prática social, própria de uma comunidade, que se realiza de acordo com os modos de ler que estão alinhados aos diferentes contextos, às múltiplas funções que orientam a leitura, às possibilidades disponíveis na sociedade para a construção de saberes e às ações dos leitores quando estão em situação de interação com os textos e com outros leitores (KLEIMAN, 2004).

Ao partir dessa perspectiva de leitura, como processo de interação, que integra um conjunto variado de fatores, também foi preciso delimitar como a argumentação pode ser entendida. Como as perspectivas que definem a argumentação são variadas e muitas não tratam especificamente das possibilidades de implementação de trabalhos teórico-práticos em espaços

2 Segundo Rosenblatt (1994), na metade do século XX, pela influência das reflexões de Dewey, os estudos em torno da linguagem e da educação foram influenciados pelo paradigma transacional que associa o conhecedor, o saber e o que é conhecido em um "processo" social de influência mútua. Dentro desse mesmo paradigma, com base em discussões realizadas mais sistematicamente desde 1980, observou-se que a separação entre professores e estudantes afeta profundamente o processo de ensino e aprendizagem porque constitui um espaço psicológico e comunicacional que potencialmente pode provocar mal-entendidos entre as intervenções dos docentes junto aos discentes. Esse espaço é chamado de distância transacional, uma variável continua nas relações educacionais, que se dão em práticas presenciais ou a distância, segundo Moore (2002). Neste artigo, essa tendência, nas duas perspectivas, é considerada na compreensão dos elementos que impactam a leitura argumentativa.

\section{LINHA DÁGUA}


escolares (NEWELL et al., 2011), optamos por partir da concepção da argumentação na perspectiva interacional e dialogal de Plantin (2008a) para propor um instrumento didáticopedagógico que pudesse auxiliar as intervenções docentes em sala de aula, visto que, para nós, "[...] ensinar não é transferir conhecimento, mas criar as possibilidades para a sua produção ou a sua construção" (FREIRE, 1996, p. 22), como explicaremos a seguir.

\subsection{A concepção de argumentação em perspectiva interacional e dialogal}

A concepção interacional e dialogal da argumentação proposta por Plantin (2008a) renuncia a ver a argumentação como algo elementar e se propõe a repensar a atividade argumentativa em um quadro mais ampliado. De acordo com Grácio (2010), uma das características mais marcantes da investigação de Plantin (2008a) acerca da argumentação é aabertura crítica às diferentes teorizações, aspecto esse que está materializado na explicação apresentada acerca da história das teorias da argumentação e da sua articulação ao longo dos tempos e na crítica às abordagens da argumentação que a restringem à persuasão ou à adesão ou à coconstrução de conclusões, por exemplo, para afirmar que a "função fundamental da argumentação é dar nome aos conflitos, permitir a expressão e o aprofundamento das diferenças" (PLANTIN, 2018[2011], p. 244), ou seja, não se trata de convencer o outro, mas conviver com ele na diferença.

Ao considerar esse aspecto, pudemos compreender que, nas situações argumentativas, os sujeitos - os interlocutores - são envolvidos nas condições em que a comunicação se realiza: o discurso, o objeto, o campo linguístico, a enunciação. Isso reforçou a assunção da língua portuguesa em sua dimensão funcional, pois os falantes se apropriam dela para expor a sua posição mediante um assunto que lhes é proposto. É nesse contexto interativo que os sujeitos se tornam responsáveis pelas suas falas numa inter-relação de construção de sentido, mas que também pode gerar inquietações decorrentes das dúvidas que podem ser introduzidas durante o processo interacional.

Plantin (2008a) concebe, assim, que a argumentação é desencadeada quando se põe em dúvida um ponto de vista, ou seja, quando há uma questão argumentativa que mobiliza os interlocutores. No modelo dialogal, “[...] o ato de duvidar é definido como um ato reativo de um interlocutor que se recusa a ratificar um turno de fala. Essa situação interacional obriga o interlocutor a argumentar, isto é, a desenvolver um discurso de justificativa" (PLANTIN, 2008a, p. 64). Percebe-se, então, que o processo argumentativo possibilita a análise de um problema ou de uma pergunta - enfim de um assunto que é posto em questão (GRÁCIO, 2010, p. 335) -, a elaboração de um ponto de vista mediante outro e ainda fornece subsídios para um sujeito se contrapor a outras opiniões.

\section{LINHA D'ÁGUA}


Nessa situação, reconhecida como uma situação $\operatorname{argumentativa}^{3}$, ocorre um tipo de argumentação que tem por base o diálogo. Um diálogo prototípico, para Plantin (2008a, p. 65), "supõe o face a face, a linguagem oral, a presença física dos interlocutores e a contínua sequência de réplicas relativamente breves" .Todavia, o modelo dialogal também recobre o diálogo polifônico, intertextual, e os outros modos de interação nos quais exista a articulação de dois discursos contraditórios (PLANTIN, 2008a, 2008b).

Assim, nas interações argumentativas em torno de um desacordo são organizadas posições distintas diante de um conflito preexistente, o que mobiliza os interlocutores a participarem das práticas de linguagem oferecendo razões para apoiar uma posição favorável ou contrária em relação ao assunto em questão, segundo regras pré-definidas em condição de igualdade aceitas pelos participantes. De acordo com Plantin (2008a), uma situação argumentativa se caracteriza como um espaço em que estão envolvidos atores que podem assumir três papéis actanciais: Proponente, Oponente e Terceiro, em uma interação tripolar.

Cada um dos actantes corresponde a uma modalidade discursiva específica: o Proponente sustenta um discurso de proposição; o Oponente, de oposição; o Terceiro levanta, aos outros, um novo discurso por meio de dúvida ou de questionamento. Ressaltamos que a noção de papel actancial não se confunde com a participação dos atores - sujeitos sociais - da comunicação argumentativa, visto que os actantes representam as posições assumidas no discurso, segundo Plantin (2008a).

Em síntese, no modelo dialogal, em situação argumentativa - definida pelo confronto de pontos de vista em contradição, em resposta a uma mesma pergunta -, os sujeitos assumem, no discurso, diferentes papéis actanciais; todos os elementos semióticos têm valor argumentativo e os envolvidos são motivados a sustentarem com argumentos a discussão que se gera a partir de uma pergunta que coloca um assunto em questão. Os actantes Proponente, Oponente e Terceiro realizam distintos atos de linguagem: o de propor, o de opor-se e o de duvidar, que podem ser assumidos em todas as partes do discurso. Ao assumir tais posições, os sujeitos apresentam argumentos, razões oferecidas como justificativas para eles.

Essa perspectiva pareceu-nos pertinente ao trabalho com a leitura argumentativa na escola, pois apresenta bases que auxiliam na busca de alternativas para promover práticas de leitura em uma perspectiva pautada no uso da linguagem e na interação. Assim, por meio de pesquisas, leituras, debates de ideias, conteúdos teóricos, jogos e análises, foi possível trabalhar com questões sociais que colaboraram com o desenvolvimento das capacidades argumentativas

3 Uma situação argumentativa, no modelo dialogal, é definida pelo confronto de pontos de vista em contradição, em resposta a uma mesma pergunta. Quando isso acontece, os interlocutores assumem papéis actanciais distintos ao formularem e sustentarem suas posições enunciativas. "[...] Em particular, as justificativas podem se fazer acompanhar de uma série de ações concretas, coorientadas pelas falas e visando tornar sensíveis as posições defendidas" (PLANTIN, 2008a, p. 64-65).

\section{LINHA DÁGUA}


dos estudantes, por meio de um trabalhado diferenciado com argumentação em sala de aula, como passaremos a descrever.

\section{Metodologia}

As bases teóricas supracitadas permitiram a organização de um trabalho aplicado em turmas de ensino fundamental a fim de sanar parte da carência de pesquisas relativas ao ensino e à aprendizagem da leitura e escrita argumentativa, tal como sugerem Newell et al. (2011). Para tanto, partimos de pesquisas exploratórias, com o objetivo de identificar quais práticas seriam mais apropriadas ao ensino da argumentação a fim de qualificar o processo de ensino e aprendizagem em escolas públicas. Assim, serão reunidos neste artigo materiais relativos a duas pesquisas distintas, realizadas no âmbito do Mestrado Profissional em Letras, da Universidade Federal de Sergipe, campus São Cristóvão (REIS, 2020; MONTE, 2020).

Por se tratarem de pesquisas intervencionistas, o material que descreveremos também pretende contribuir com a ampliação de trabalhos em torno da argumentação em outras turmas da educação básica, visto que as propostas desenvolvidas por duas professoras vinculadas a duas distintas escolas, uma localizada na Bahia e outra em Sergipe, têm em comum o esforço em qualificar o ensino da leitura argumentativa na perspectiva dialogal e interacional.

Nas pesquisas empreendidas por Louriane Reis (2020) e Nadija Monte (2020), os saberes de cada professora-pesquisadora foram articulados às ideias reunidas em materiais bibliográficos de dois tipos: aspectos teóricos relativos ao modelo dialogal de Plantin (2008a, 2008b, 2018) e aspectos metodológicos que permitiram prospectar atividades didáticas que poderiam mobilizar a teoria em práticas escolares, conforme Plantin e Muñoz (2011) e Muñoz e Musci (2013).

No plano teórico, desde a metade do século XX até hoje, observamos uma produção crescente de estudos em torno da argumentação em diferentes perspectivas, gerando profusão de trabalhos no campo retórico, como os alinhados à Nova Retórica; no campo da lógica, como os formulados pela Lógica Informal; e no campo linguístico, como os propostos por Anscombre e Ducrot (1983), relativos à argumentação na língua. Além disso, a diversidade de gêneros orais, escritos e multimodais em circulação na sociedade tem gerado um interesse pela argumentação por profissionais em diferentes áreas de conhecimento. Entendemos que a convivência com esses gêneros no cotidiano requer dos estudantes certas condições para interagir com eles e interpretá-los.

No plano metodológico, as professoras-pesquisadoras buscaram atender aos documentos oficiais que orientam as práticas dos professores de língua portuguesa - como os Parâmetros Curriculares Nacionais, de Língua Portuguesa (BRASIL, 1998a, 1998b), assim como os PCN+ (BRASIL, 2002), e a Base Nacional Comum Curricular (BRASIL, 2018),

\section{LINHA DÁGUA}


doravante BNCC. Esses materiais explicitam a necessidade de os professores atentarem para o ensino da argumentação. Desde 1998, portanto, os professores são orientados a reconhecer que o domínio dos recursos linguísticos, discursivos e argumentativos pelos estudantes possibilita uma participação mais efetiva nas práticas sociais de linguagem (AZEVEDO, 2016). Especificamente, na BNCC, em uma das competências gerais da educação básica (7), o docente é encaminhado a proporcionar aos estudantes:

Argumentar com base em fatos, dados e informações confiáveis, para formular, negociar e defender ideias, pontos de vista e decisões comuns que respeitem e promovam os direitos humanos, a consciência socioambiental e o consumo responsável em âmbito local, regional e global, com posicionamento ético em relação ao cuidado de si mesmo, dos outros e do planeta" (BRASIL, 2018, p. 9).

Essa competência 7 pressupõe que todos os professores teriam formação específica para compreender e garantir a apropriação das ideias em suas práticas escolares, o que não tem sido visualizado nos espaços escolares nos quais as professoras-pesquisadoras se inserem. Como o trabalho com argumentação na escola exige de professores e estudantes o reconhecimento das regularidades intrínsecas aos fenômenos discursivos e um esclarecimento quanto aos conceitos mobilizados em torno da argumentação, entendemos que tal competência motiva, entre outras possibilidades, o trabalho específico com a leitura argumentativa.

Esse tipo de proposta didático-pedagógica atende também a necessidades dos contextos escolares, uma vez que, em ambas as escolas, o estudo sistematizado da argumentação era pouco privilegiado e, quando algo era realizado, estava restrito à transmissão de um esquema pré-estabelecido pelo professor para atender a um objetivo específico, como preparar o estudante a obter sucesso na redação do Exame Nacional do Ensino Médio (ENEM). As professoras-pesquisadoras notavam também que, tanto nos documentos oficiais nacionais e estaduais quanto em cada ambiente escolar, faltava orientação específica quanto ao conceito de argumentação e de como as atividades escolares poderiam ser planejadas. Por isso, foi necessário buscar meios para ampliar e qualificar as práticas pedagógicas que visavam ao desenvolvimento de capacidades argumentativas.

\subsection{Caracterização dos espaços escolares}

O presente artigo descreve a realização de dois trabalhos que foram desenvolvidos em Sergipe e Bahia, em turmas do $8^{\circ}$ e do $9^{\circ}$ ano do ensino fundamental situadas nas cidades de Neópolis e Araçás, respectivamente. Para que se conheçam algumas das características de cada local, elaboramos o quadro 1 a seguir. 
Quadro 1. Contextos escolares de duas distintas cidades brasileiras

\begin{tabular}{|c|c|c|}
\hline Características & $\begin{array}{c}\text { EXPERIÊNCIA } 1 \\
\text { Escola em Neópolis / SE }\end{array}$ & $\begin{array}{c}\text { EXPERIÊNCIA } 2 \\
\text { Escola em Aracás / BA }\end{array}$ \\
\hline $\begin{array}{l}\text { 1. Histórico da } \\
\text { cidade }\end{array}$ & $\begin{array}{l}\text { Elevada à categoria de cidade apenas em } \\
\text { 1940, embora tenha surgido como uma aldeia } \\
\text { no século XVII. É conhecida como a Capital } \\
\text { Sergipana do Frevo pelo tradicional carnaval } \\
\text { de rua que preserva, com os enormes bonecos } \\
\text { conduzindo os foliões no Bloco do Zé } \\
\text { Pereira, ao estilo de Olinda. É banhada pelas } \\
\text { águas do Rio São Francisco. }\end{array}$ & $\begin{array}{l}\text { Embora a história da cidade tenha início em } \\
\text { 1831, passa à categoria de cidade apenas em } \\
\text { 1989. A banda de música Pioneirus, de estilo } \\
\text { fanfarra/filarmônica, que conta com } 70 \\
\text { membros, destaca-se, entre outras } \\
\text { manifestações musicais na cidade. É uma } \\
\text { região com predominância econômica na } \\
\text { agricultura, produzindo abacate. }\end{array}$ \\
\hline $\begin{array}{l}\text { 2. População e } \\
\text { área da cidade }\end{array}$ & $\begin{array}{l}\text { Possui população estimada de } 18.703 \text { (em } \\
\text { 2020) e uma área de } 249,9 \mathrm{~km}^{2} \text {. }\end{array}$ & $\begin{array}{l}\text { Possui população estimada de } 12.208 \text { (em } \\
\text { 2020) e uma área de } 474,577 \mathrm{~km}^{2} \text {. }\end{array}$ \\
\hline $\begin{array}{l}\text { 3. Perfil } \\
\text { populacional }\end{array}$ & $\begin{array}{l}\text { Em 2018, o município apresentava } 22.9 \% \text { de } \\
\text { domicílios com esgotamento sanitário } \\
\text { adequado e } 56.4 \% \text { de domicílios urbanos em } \\
\text { vias públicas. Além da população urbana, } 21 \\
\text { povoados compõem a zona rural. A média } \\
\text { salarial mensal era de } 1.8 \text { salários mínimos. }\end{array}$ & $\begin{array}{l}\text { Em 2018, o município apresentava } 2.7 \% \text { de } \\
\text { domicílios com esgotamento sanitário } \\
\text { adequado. } 52.9 \% \text { dos domicílios tinham } \\
\text { rendimento mensal de até meio salário } \\
\text { mínimo; a média salarial mensal era de } 1.4 \\
\text { salários mínimos. }\end{array}$ \\
\hline 4. Perfil da escola & $\begin{array}{l}\text { A Escola Estadual Aminthas Diniz de Aguiar } \\
\text { Dantas funciona em prédio novo, localizado } \\
\text { na entrada/saída de Neópolis. Possui } \\
\text { problemas de infraestrutura que impedem o } \\
\text { bom andamento das ações pedagógicas, } \\
\text { dentre os quais oscilação na rede elétrica, fios } \\
\text { soltos, falta de equipamento para reprodução } \\
\text { de materiais etc. }\end{array}$ & $\begin{array}{l}\text { O Colégio Municipal de Araçás dispõe de } \\
\text { ampla estrutura física, incluindo laboratório, } \\
\text { quadra de esportes e área de lazer. É situado } \\
\text { no centro da cidade e acolhe alunos nos três } \\
\text { turnos. Quanto à origem dos estudantes, são } \\
\text { provenientes da zona urbana, da zona rural e } \\
\text { de comunidades quilombolas. }\end{array}$ \\
\hline 5. IDEB da escola & Em 2017: 4.4; em 2019: 5.3. & Em 2017: 3.6; em 2019: 4.4. \\
\hline 6. IDEB - Brasil & Estadual: em 2017: 4.5; em 2019: 4.7. & Municipal: em 2017: 4.3; em 2019: 4.5. \\
\hline $\begin{array}{l}\text { 7. Faixa etária } \\
\text { dos estudantes }\end{array}$ & $\begin{array}{l}12 \text { aos } 18 \text { anos, com assimetria na relação } \\
\text { idade/série. }\end{array}$ & $\begin{array}{l}14 \text { e } 15 \text { anos, com assimetria na relação } \\
\text { idade/série. }\end{array}$ \\
\hline $\begin{array}{l}\text { 8. Perfil dos } \\
\text { estudantes }\end{array}$ & $\begin{array}{l}\text { Alguns estudantes são advindos do interior } \\
\text { próximo, dependem do transporte escolar ou } \\
\text { vão a pé à escola e sofrem bullying. Grupo } \\
\text { heterogêneo, com dificuldades de leitura e } \\
\text { escrita. }\end{array}$ & $\begin{array}{l}\text { O perfil de estudantes é diversificado em } \\
\text { termos socioeconômicos. Alguns são mais } \\
\text { carentes ou ainda são membros de lares } \\
\text { carentes do estreitamento de laços afetivos. } \\
\text { Grupo com dificuldades específicas quanto } \\
\text { ao processo de produção escrita. }\end{array}$ \\
\hline
\end{tabular}

Fontes: https://www.ibge.gov.br/cidades-e-estados e http://ideb.inep.gov.br/resultado Acesso em: 30. abr. 2021.

Como se observa no quadro 1 , as escolas apontadas, apesar de localizadas em diferentes estados, possuíam em comum, antes do início do projeto: a acolhida de estudantes provenientes tanto da zona urbana quanto rural $(3 ; 4)$, com perfil socioeconômico baixo (4), com defasagem idade/série (7) e que apresentavam dificuldades de leitura e escrita (8). Tais condições exigiram estudos específicos acerca das possibilidades de ensino de leitura, de interpretação de textos argumentativos e de estratégias didáticas diversificadas para atender à heterogeneidade dos grupos de estudantes implicados em cada pesquisa.

\section{LINHA DÁGUA}


Em função dessa realidade, em ambos os casos, como primeiro passo investigativo, foram realizadas atividades diagnósticas, a fim de identificar as capacidades de linguagem dos estudantes e delimitar os pontos que mereceriam maior atenção no planejamento das atividades. Após a análise dos resultados obtidos nas sondagens, o trabalho com a leitura argumentativa foi organizado em duas frentes: na experiência 1, que gerou como produto do Mestrado Profissional um Módulo didático ${ }^{4}$, e na experiência 2, organizada em três blocos de atividades, detalhados em um Caderno Pedagógico ${ }^{5}$, do qual recortamos apenas as atividades concernentes à leitura.

Na sequência, passamos a descrever como o trabalho pode ser organizado para atender a essas duas linhas de trabalho. Também pretendemos destacar como a leitura argumentativa contribui com o aprimoramento da capacidade de compreensão textual, uma vez que possibilita observar a sistematização das ideias em argumentos e contra-argumentos em textos em que se observa confronto de posições e quais recursos linguísticos orientam a perceber a articulação entre os papéis actanciais, o que permite identificar a assunção de posições discursivas ao longo de um texto.

Para tanto, optou-se por reunir, separadamente, os dados da expleriência 1, empreendida por Nadija Monte, e da experiência 2, praticada por Louriane Reis, juntamente com os resultados observados durante a pesquisa realizada em 2018-2019, antes de propor uma síntese que propõe um modo de concretizar o trabalho com a leitura argumentativa no ensino fundamental. Isso porque cada pesquisa exploratória seguiu um planejamento adequado à realidade à qual estava associada e flexível às necessidades que foram sendo identificadas ao longo do desenvovimento das experiências.

\section{Descrição das intervenções didático-pedagógicas e dos resultados obtidos}

As experiências realizadas no âmbito do Profletras, com base nas ideias de Plantin (2008a), partiram da constatação de que as argumentações têm suas raízes nas trocas linguísticas ordinárias, cotidianas, nos discursos fortemente dependentes do contexto, que constitui um ponto de partida para as investigações voltadas às práticas de linguagem. Assim, para nós, a argumentação se faz presente tanto nas interações informais, como em uma conversa entre familiares ou amigos, quanto nos textos mais complexos, como em um artigo acadêmico que segue uma estrutura de alta formalização.

4 O material completo encontra-se disponível em: https://ri.ufs.br/bitstream/riufs/13621/2/NADIJA SANTOS _MONTE-Modulo_Didatico.pdf., https://ri.ufs.br/bitstream/riufs/13620/2/NADIJA_SANTOS_MONTE.pdf

5 O material completo encontra-se disponível em: https://ri.ufs.br/bitstream/riufs/13619/2/LOURIANE_ RIBEIRO REIS.pdf

\section{LINHA DÁGUA}




\subsection{Atividades de sondagem}

Na experiência 1, os estudantes compararam dois jornais de Sergipe (Jornal da Cidade e Correio de Sergipe, em circulação em novembro de 2018), a fim de compreender a composição do material, a organização dos elementos da capa, como a manchete e a chamada, e a ordem das informações em uma notícia referente a uma pessoa do interior do município deles. Muitos desconheciam as características desse veículo de comunicação, por isso demonstraram curiosidade, e a interação foi intensa. Após o manuseio do material impresso uma experiência inédita para quase todos os estudantes, pois não há jornais produzidos na cidade, e a função do material físico limitava-se a embrulho -, a professora propôs algumas questões que versavam acerca do papel social da escrita jornalística e dos tipos de gêneros encontrados no jornal.

Dos quatorze estudantes que participaram dessa atividade inicial, metade conhecia a palavra argumentação, uma parte menor conseguia caracterizar um texto argumentativo e apenas dois sugeriram objetivos para a produção de um texto argumentativo. A totalidade não conhecia os operadores linguísticos que compõem textos marcados pela argumentação, e somente um estudante afirmou saber identificar um operador argumentativo, mas não foi capaz de localizá-lo no jornal em mãos. Três estudantes declararam ter ouvido falar de contraargumentação e conseguiram explicitar, em linhas gerais, em que tipo de situação textos contraargumentativos podem ser redigidos.

Com relação às questões relativas a uma notícia encontrada no Correio de Sergipe, que tematizava o tratamento de uma criança internada com um caso grave de calazar, os estudantes demonstraram dificuldade em notar as trocas interacionais que serviram de referência para a produção da notícia.

Na experiência 2, a sondagem observou tanto as capacidades de leitura quanto de produção textual, visto que o objetivo final da pesquisa estava voltada à produção de gêneros preponderantemente argumentativos, uma vez que Louriane Reis (2020), ancorada em Dolz (1995, p. 67, tradução nossa), reconhecia que "a escrita permite aos alunos tomar consciência de certas dimensões linguístico-discursivas que nem sempre são tomadas em conta pelos leitores com dificuldades ou em fase de aprendizagem da leitura e que, por isso, constituem um obstáculo para a compreensão de um texto".

Assim, os estudantes tiveram, em primeiro lugar, que analisar uma capa da revista Veja,

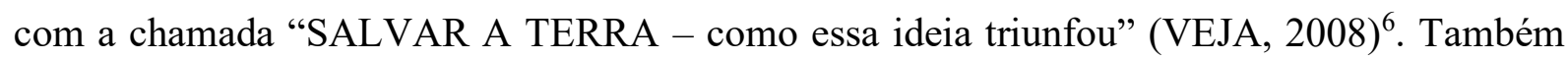
participaram de outras atividades com foco na análise da argumentação e, depois, produziram um texto com base na discussão realizada em torno da capa da revista.

Em relação à capa da revista, muitos estudantes não conseguiram identificar a questão polêmica abordada nela nem conseguiram antecipar posicionamentos favoráveis ou contrários

6 Disponível em: https://bit.ly/3aqmd2y.

\section{LINHA DÁGUA}


à ideia levantada. Na produção do artigo de opinião, após as discussões em torno da capa, os estudantes descreveram experiências em que observaram situação de agressão ao meio ambiente ou apresentaram juízos de valor relativos aos comportamentos das pessoas, incluindo o modo como se vestem. Nos trechos em que se observava algum posicionamento em torno da temática, notamos um repertório cultural restrito, além de problemas diversos na construção composicional do gênero solicitado, bem como falhas na estrutura sintática das sentenças, que provocavam dúvidas acerca dos posicionamentos assumidos.

Embora distintas, as sondagens indicaram que o trabalho com a leitura argumentativa precisaria contemplar atividades de todos os níveis (linguístico, textual, cognitivo, comunicativo e discursivo), além de tratar da composição de argumentos nas interações pela linguagem. Assim, cada professora privilegiou os meios disponíveis em cada ambiente escolar para desenvolver uma pesquisa de caráter intervencionista.

\subsection{A leitura argumentativa de gêneros jornalísticos (experiência 1)}

No planejamento do Módulo Didático ${ }^{7}$, Nadija Monte organizou as atividades em três etapas: 1. problematização inicial; 2. organização do conhecimento; 3. aplicação do conhecimento. A primeira etapa foi desenvolvida por meio de um jogo intitulado "Caminhada dos contra-argumentos", cujo objetivo era incitar os estudantes a perceberem como os questionamentos promovem a assunção acerca dos diferentes papéis actanciais (Proponente, Oponente e Terceiro) em uma situação de interação argumentativa. Além disso, o jogo permitiu perceber a relação entre argumento/discurso e contra-argumento/contradiscurso, a partir de uma questão problematizadora (PLANTIN, 2011).

Para o jogo, os estudantes foram divididos em duas equipes (representadas pelas cores azul e lilás), que discutiram: "O celular deve ser proibido em sala de aula". Os argumentos apresentados pelas equipes eram avaliados em função do uso de elementos linguísticodiscursivos apropriados e da apresentação de uma contraposição ao discurso do outro. Era considerado um contra-argumento fraco aquele que apresentava ausência de elementos linguísticos coerentes ou uma opinião carente de justificativas; um contra-argumento forte apresentava composição textual, conteúdo e organização lógica coerentes. Os argumentos de partida foram oferecidos na forma de cartas do jogo, e a professora construiu esse material a partir de manifestações de integrantes da comunidade escolar. Quando uma equipe não conseguia responder, a outra recebia uma tentativa, mas com um tempo reduzido. A avaliação era realizada pela professora, mas os estudantes precisavam estar de acordo. Cada acerto permitia subir um degrau, e a equipe que conseguisse chegar ao topo em primeiro lugar ganhava o jogo.

As bases conceituais que orientaram a composição de um Módulo Didático podem ser encontradas em Azevedo e Freitag (2020).

\section{LINHA DÁGUA}


Abordar a contra-argumentação por meio de um jogo possibilitou aos estudantes entender a relação entre uma questão problematizadora e os possíveis argumentos e contraargumentos ligados a ela, de maneira interativa e lúdica. Os estudantes tiveram que analisar os argumentos de partida, relacioná-los aos contra-argumentos possíveis, discutir como apresentálos e avaliar as colocações de cada equipe, com a mediação da professora e a participação de todos. Além disso, em um momento posterior ao jogo, puderam retomar coletivamente tudo o que foi realizado.

Na segunda etapa, na fase de organização do conhecimento, para aprofundar a relação entre a questão problematizadora e a escolha pelos papéis actanciais, ocorreu um trabalho organizado em três atividades: a análise de uma entrevista jornalística, análise colaborativa de uma notícia e análise dos operadores contra-argumentativos encontrados em textos voltados ao público infanto-juvenil. Na entrevista com Talysson de Valmir, deputado eleito em 2018, pela cidade de Itabaiana-SE, os estudantes, divididos em dois grupos (A e B), tiveram que marcar os trechos em que se encontravam diferentes papéis actanciais (de Proponente ou concordante ${ }^{8}$, de Oponente e de Terceiro).

O confronto de marcações de cada grupo permitiu, sobretudo, distinguir os atores sociais dos papéis actanciais, além de possibilitar a comparação de trechos assinalados na entrevista encontrada no jornal. A seleção de trechos gerou contraposição de visões e de entendimentos; já as justificativas orais serviram tanto para gerar interação entre os estudantes, que precisavam justificar suas escolhas, quanto para a professora-pesquisadora avaliar a ampliação das capacidades de leitura, especialmente quando, ao final, os estudantes precisaram produzir sínteses dos conceitos aprendidos.

$\mathrm{Na}$ análise colaborativa de uma notícia ("Tototós resistem ao tempo e à modernidade" do Jornal da Cidade), novamente a turma foi dividida em duas equipes. A professorapesquisadora leu o texto, e houve uma breve conversa acerca do assunto em questão no texto, bem como dos papéis actanciais que poderiam ser assumidos no texto. Como a notícia continha um depoimento, além da voz do jornalista, foi possível rever a noção de atores sociais e de papéis actanciais, que foram destacados com cores distintas. As justificativas para a avaliação dos papéis actanciais foram registradas na cópia do texto, entregue a cada um para que pudesse retomar as ideias posteriormente.

$\mathrm{Na}$ análise dos operadores que favorecem a contra-argumentação, Nadija Monte procurou destacar o valor semântico de cada um, segundo Pauliukonis (2014). Para a realização dessa atividade, a partir de uma lista com os principais operadores contra-argumentativos e as respectivas explicações da carga semântica, os estudantes tiveram que analisar textos de revistas infanto-juvenis (Atrevida e Todateen, do jornal on-line Correio Braziliense e do Jornal da

8 Para que houvesse um melhor entendimento por parte dos estudantes, o termo "concordante" foi usado como sinônimo para Proponente, uma vez que este concorda com a questão posta, direciona sua resposta para o sim, apresenta elementos favoráveis, torna-se um "aliado", como bem citou um dos estudantes durante a realização do jogo.

\section{LINHA DÁGUA}


Cidade). Os assuntos eram de interesse dos adolescentes (o problema de acne, a amizade entre meninos e meninas, o uso da tecnologia e afins), logo, geraram interesse em conhecer as posições favoráveis e contrárias a cada situação. Após a identificação dos operadores contraargumentativos presentes nos trechos selecionados pelos estudantes, houve uma análise comparativa com relação à carga semântica de cada um, permitindo o esclarecimento de dúvidas. Para Plantin (2008, p. 64), "a atividade argumentativa é desencadeada quando se põe em dúvida um ponto de vista", e ter a oportunidade de confirmar isso em diferentes gêneros jornalísticos promoveu a articulação entre os conhecimentos de diferentes níveis.

Na terceira etapa, os estudantes realizaram individualmente um exercício que propunha a recuperação de tudo o que foi estudado ao longo do Módulo Didático. Cada um recebeu uma cópia da entrevista que o Jornal da Cidade produziu com a fonoaudióloga Aline Fontes, especialista em voz, intitulada "Aprender oratória desde criança promove melhora no aprendizado escolar". Inicialmente, tiveram que identificar qual dos papéis actanciais encontrados no material (de Proponente ou Concordante, Oponente ou Terceiro) para, em seguida, cada um participar de uma discussão acerca do assunto em questão. O posicionamento favorável ou não às afirmações da especialista também foi transcrito em um material entregue pela professora, o que possibilitou acompanhar melhor a evolução das aprendizagens.

O processo interativo e dialogal, com base no tríptico argumentativo, possibilitou aos estudantes perceber que a identificação de posições discursivas se apoia no uso de recursos linguísticos, no modo como o texto está organizado, nas relações estabelecias no/pelo discurso, nas escolhas discursivas que são representadas em um texto, no modo como cada um avalia o dizer alheio e reage a ele, ou seja, que a leitura argumentativa requer a articulação de um conjunto variado de elementos sempre nos confrontando com textos marcados pela argumentação, sejam eles orais ou escritos.

\subsection{A leitura argumentativa de gêneros jornalísticos (experiência 2)}

Reafirmamos que a proposta de trabalho com a argumentação realizada em Araçás foi composta de três blocos - bloco I: atividades que exploraram a argumentação em situações sociais de interação comunicativa; bloco II: conceitos teóricos da argumentação a partir de uma sequência didática; bloco III: produção de um jornal mural -, mas apenas três atividades do bloco são recuperadas neste artigo.

Como destacamos anteriormente, a vivência de uma situação argumentativa é um meio potente para promover o entendimento de conceitos e o uso de recursos linguístico-discursivos na produção argumentativa. Assim, no planejamento elaborado por Louriane Reis foram incluídos a análise de um debate oral, produzido pelos próprios estudantes na escola, uma análise comparativa de textos e um jogo. A contínua articulação entre atividades orais e escritas, em ambas as experiências, confirmou ser uma estratégia relevante no ensino da argumentação.

\section{LINHA D'́GUA}


O debate foi produzido no bloco I e partiu de uma questão que inquietava os estudantes do $9^{\circ}$ ano do ensino fundamental do Colégio Municipal de Araçás: "deve-se liberar o uso do celular em sala de aula?" Em 2019, o assunto estava posto em questão e mobilizava diferentes atores sociais no contexto escolar, visto que os professores reclamavam da tentativa de utilização do equipamento entre seus pares na sala dos professores, os estudantes solicitavam o uso do recurso tecnológico, e a direção proibia a presença do aparelho na sala de aula. Diante dessa questão problematizadora e do confronto de posições, a professora-pesquisadora propôs aos estudantes preparar um protodebate ${ }^{9}$ com o coordenador em classe. A preparação para o protodebate exigiu a leitura de variados materiais a fim de que os estudantes pudessem preparar contra-argumentações frente à proibição da direção da escola. O envolvimento pessoal de cada estudante frente ao assunto em questão minimizou algumas dificuldades na compreensão de variados textos prospectados pelos estudantes, sob a orientação da professora, pois o interesse em encontrar argumentos favoráveis ao uso do celular na escola motivava todos. A apresentação prévia de argumentos favoráveis e contrários à manutenção do impedimento de uso do celular na escola pelos próprios estudantes, antes do protodebate com um representante institucional, constituiu-se como uma etapa importante para que pudessem confrontar os argumentos que poderiam ser apresentados pelo coordenador da escola, que aceitou discutir a questão com a turma.

A atividade foi gravada e configurou o primeiro material oferecido para a leitura argumentativa. Como todos os alunos estavam envolvidos durante a presença do coordenador na classe, ter a oportunidade de rever a discussão, os argumentos apresentados pelo coordenador, os contra-argumentos expostos pelos estudantes, a análise dos papéis actanciais assumidos tanto por ele quanto pelos estudantes, os operadores argumentativos que possibilitaram demarcar um posicionamento contrário etc. garantiu um estudo que interessou a todos e que poucas vezes tinha sido possível na escola. Retomar como os argumentos foram compostos e os efeitos provocados durante a realização do protodebate permitiu aos estudantes entender o funcionamento da argumentação em uma situação específica de uso da linguagem, mas que poderia ser ampliado para outras circunstâncias. A revisão do vídeo proporcionou muitas anotações coletivas e individuais, que serviram de referência para a análise comparativa de textos e a participação no "Jogo da argumentação".

A análise comparativa de dois textos, que discutiam o problema da "gravidez na adolescência" - um trecho retirado da Wikipédia foi apresentado em comparação com um outro, produzido por Gilmaci Santos, deputado estadual da Assembleia Legislativa do Estado de São Paulo -, serviu a uma finalidade específica: auxiliar os estudantes a compreenderem o esquema argumentativo mínimo, sugerido por Plantin e Muñoz (2011). Para tanto, foi organizado um material de referência para os estudantes (Quadro 2), a fim de que pudessem utilizar durante a leitura dos textos.

9 Utilizou-se o termo "protodebate" por se tratar de uma adaptação de um debate propriamente dito.

\section{LINHA DÁGUA}


Quadro 2. Esquema argumentativo mínimo

Dados: Crença ou fato.

Lei de passagem: (= permissão) para inferir (extrair, deduzir). Atua como elo entre o dado e a conclusão, transferindo a adesão concedida. São geralmente princípios ou convenções aceitos que assumem a forma de declarações.

Conclusão: uma afirmação funciona como conclusão quando surge a relação entre os dados e a lei de passagem, como consequência esperada.

Argumento: dado que se baseia em uma lei de passagem adequada. $\mathrm{O}$ argumento começa com um dado, crença ou fato e adquire a categoria de argumento quando, através da lei de passagem, leva com êxito o interlocutor à conclusão.

Os dados/fatos adquirem a função de argumento quando são sustentados por uma lei de passagem adequada.

\section{Exemplo:}

Dado: Aumentou a venda de imóveis em 30\%.

Lei de passagem: $\mathrm{O}$ aumento na venda de imóveis indica uma melhora da economia.

Conclusão: A situação econômica melhorou.

Argumento: O aumento da venda de imóveis em 30\% melhorou a situação econômica.

- A lei de passagem pode ser questionada ou criticada pelo interlocutor. Pode haver uma resposta (contraargumentação) possível de um interlocutor que não foi convencido pela lei de passagem.

Fonte: Elaborado por Louriane Reis a partir de Plantin e Muñoz (2011).

Com base no esquema argumentativo mínimo, proposto por Plantin e Muñoz (2011) a partir do trabalho de Toulmin (2006 [1958]), os estudantes puderam perceber que um argumento não consiste em um conjunto simples de proposições, mas possui uma estrutura específica. Uma premissa e uma conclusão devem sempre estar presentes nessa estrutura, e a conclusão deve ser inferida da premissa, considerando a lei de passagem. No argumento, a premissa (dado) assume a forma de uma afirmação que será aceita como válida em virtude de sua relação implícita ou explícita com outra afirmação mais geral (lei de passagem) que permite chegar à conclusão. Esse tipo de trabalho permitiu aos estudantes perceberem que premissa $\mathrm{e}$ conclusão não possuem o mesmo status, ou seja, enquanto a premissa parte de uma informação recolhida na sociedade ou de uma crença, a conclusão é o resultado de uma inferência apoiada em uma "lei de passagem" em vigor na sociedade (PLANTIN, MUÑOZ, 2011). A análise dos elementos constitutivos de um raciocínio argumentativo também possibilitou notar como é possível contrapor posições ao que pode ter sido apresentado inicialmente, o que incluiu a observação de expressões que poderiam ser utilizadas para:

Formular a tese: "Eu recomendo", "Eu proponho", "Eu sugiro", "Eu peço".

Introduzir argumentos: "Porque", "considerando que", "ao levar em conta que".

Resumir e concluir: "É importante”, "É necessário", "É urgente” (REIS, 2020, p. 133).

\section{LINHA D'́GUA}


Esses recursos linguístico-textuais auxiliam a identificar cada parte do raciocínio, por isso a professora orientou os estudantes a observarem que os conteúdos colocados em contraste (por meio da associação ou dissociação de ideias) e as expressões linguísticas, que podem auxiliar a perceber quando uma opinião ou posição está em destaque - como os recursos empregados para obter progressão temática e o uso de articuladores textuais (KOCH; ELIAS, 2017) -, colaboram com a construção de posições argumentativas.

Como esse tipo de estudo era novo para os estudantes, a professora-pesquisadora organizou o "Jogo da argumentação", um jogo físico, no formato de cartas, cujos objetivos eram retomar esses conceitos e auxiliar a apreensão por parte da turma. Nas cartas são encontrados esquemas argumentativos mínimos, sempre com a ausência de um dos três elementos (premissa, lei de passagem ou conclusão), para que os estudantes pudessem completar os raciocínios. Organizados em duplas, os estudantes retiravam uma carta do monte, completavam o esquema sorteado, o mediador aprovava ou não a resposta, gerando a pontuação correspondente, em caso de acerto.

O conjunto completo de atividades realizadas ao longo do projeto de pesquisa de Louriane Reis, no qual se encontram as três atividades que foram reunidas neste artigo, procurou desenvolver a prática da leitura argumentativa associada à produção escrita de gêneros jornalísticos. Também percebemos um traço marcante nas práticas pedagógicas dessa professora-pesquisadora: a variabilidade didática (BRU, 1991; FREIRE, 1996; PERRENOUD, 2000; PLANTIN, MUNÓZ, 2011), que procura atender aos estilos cognitivos, às capacidades distintas dos estudantes, às variedades nas representações dos saberes, à compreensão crítica dos argumentos e às diferenças culturais.

No bloco III, os estudantes puderam assumir a posição de escritores responsáveis pela composição do jornal mural, direcionado à comunidade escolar e araçaense, o que permitiu realizar prática autêntica de produção textual com função social.

\subsection{Discussão dos resultados observados nas experiências 1 e 2}

Com base nas experiências 1 e 2, procuramos indicar como o ensino da leitura argumentativa pode ser efetivado em turmas do ensino fundamental (anos finais). As duas pesquisas realizadas no âmbito do Profletras, entre 2018 e 2019, confirmaram que esse tipo de leitura exige dos professores o planejamento de práticas específicas, pois os estudantes precisam ter acesso a conhecimentos que permitem compreender os usos sociais da linguagem em uma perspectiva diferenciada, a da argumentação. Para tanto, faz-se necessária a escolha de uma das referências existentes no campo dos estudos da argumentação, por isso, neste trabalho, que considera a leitura uma atividade interacional, optou-se pelo modelo dialogal da argumentação.

\section{LINHA D'ÁGUA}


Como uma síntese dos trabalhos descritos e considerando outras pesquisas relacionadas ao ensino da leitura e da argumentação reunidas neste artigo, organizamos seis princípios que podem orientar práticas de ensino de leitura argumentativa.

1. Observar que todos os discursos marcados pela argumentação e materializados em textos apresentam um assunto colocado em questão. Isso pode acontecer por meio da resposta a uma questão problematizadora ou por meio de associações e dissociações entre ideias discutidas pelo autor (PLANTIN, 2008a; GRÁCIO, 2010).

2. Selecionar materiais de leitura que apresentam posições contrastantes, em que seja possível observar o ato de linguagem de propor, opor e duvidar, pois esses atos estão alinhados aos três papéis actanciais (do proponente, oponente e terceiro) que demarcam as posições argumentativas assumidas ao longo do texto (PLANTIN, 2008a; 2008b; PLANTIN e MUÑOZ, 2011; MUÑOZ e MUSCI, 2013; MONTE, 2020; REIS, 2020).

3. Acompanhar a sequência de um discurso que enfatiza uma questão argumentativa requer atenção para recursos linguísticos e textuais, como o uso dos operadores argumentativos em diferentes partes do texto, a articulação entre as partes do texto, as escolhas lexicais etc., ou seja, é necessário observar a articulação entre o nível linguístico, textual e comunicativo que impactam os níveis discursivo e argumentativo (KOCH e ELIAS, 2017; MONTE, 2020; REIS, 2020).

4. Organizar tarefas abertas, fundadas em diferentes contextos comunicativos e que possibilitem uma pluralidade de posições discursivas, e tarefas fechadas, que permitam distinguir um modo de tematizar uma questão em relação a outros, identificar um esquema argumentativo mínimo ou quais operadores contraargumentativos foram colocados em uso, por exemplo, precisam ser previstas ao longo do trabalho com a leitura argumentativa, concretizando, assim, um trabalho pedagógico com variabilidade didática (BRU, 1991; FREIRE, 1996; PERRENOUD, 2000; PLANTIN e MUÑOZ, 2011).

5. Organizar práticas de leitura colaborativa entre os diferentes parceiros da relação pedagógica para que os estudantes possam comparar percepções e entendimentos (MONTE, 2020; REIS, 2020, REZNITSKAYA et al., 2001; REZNITSKAYA et al., 2009).

6. Criar oportunidades para os estudantes participarem de práticas de leitura argumentativa com valor social, visto que isso os motiva a interagir com os discursos alheios e torna possível o desenvolvimento de atitudes críticas alinhadas aos usos sociais da linguagem (KLEIMAN, 2004; GRÁCIO, 2010; REIS, 2020).

Embora esses princípios não possam recobrir todos os aspectos implicados na leitura argumentativa (NEWELL et al., 2011), eles indicam possibilidades para o encaminhamento de

\section{LINHA DÁGUA}


propostas didático-pedagógicas favoráveis à exploração de diferentes aspectos ligados à sua efetiva realização em salas de aula da educação básica. Ao final da concretização das experiências 1 e 2, ambas as professoras-pesquisadoras confirmaram a necessidade de continuarem aprofundando os estudos relativos tanto à leitura quanto à argumentação.

\section{Considerações finais}

Ao assumir que a leitura argumentativa ainda carece de estudos que auxiliem os professores a viabilizar seu ensino na educação básica, procuramos destacar, neste artigo, alguns pontos que podem colaborar com a realização de um trabalho pedagógico alinhado às necessidades de muitos estudantes e compatível com a dinâmica realidade própria das sociedades contemporâneas ocidentais.

Assim, entendemos que para compor práticas escolares favoráveis ao desenvolvimento da leitura argumentativa, que se torna necessária tanto em função da diversidade dos usos da linguagem no Brasil e mundo afora quanto em atendimento às exigências de documentos oficiais, como a BNCC (BRASIL, 2018), os/as docentes que atuam na educação básica precisam aprofundar os estudos relativos à compreensão leitora e à argumentação. Considerando, contudo, que em ambos os campos há muitas perspectivas disponíveis para a composição de experiências escolares, optamos por assumir nesta reflexão que a leitura é um tipo de ação complexa e interacional que envolve elementos pertencentes a diferentes níveis (linguístico, textual, comunicacional e discursivo) e propusemos articular essa concepção ao estudo da argumentação em perspectiva interacional e dialogal, com base em Plantin (2008a; 2008b).

Com base nos estudos teóricos e em duas pesquisas intervencionistas, realizadas no âmbito do Profletras, pudemos sugerir um conjunto de atividades que colaboram com o desenvolvimento da leitura argumentativa e delimitar seis princípios que podem orientar outras práticas que possam ser planejadas por professores em atuação tanto na rede pública quanto privada. Esses princípios reúnem aspectos que não podem ser perdidos de vista quando o trabalho com a leitura argumentativa ocorre de maneira interacional e dialógica e quando se quer propiciar aprendizagens que sejam aplicadas aos diferentes contextos escolares e sociais.

Por agrupar resultados de duas pesquisas exploratórias, este artigo registra pontos que estão abertos a interlocuções tanto no âmbito dos estudos da linguagem e da argumentação quanto no da educação, por isso esperamos estabelecer novos diálogos com outros professores e pesquisadores interessados na mesma temática. 


\section{Referências}

ANSCOMBRE, J.-C.; DUCROT, O. L'Argumentation dans la langue. Bruxelas: Mardaga, 1983.

AZEVEDO, I. C. M. Organização de textos dissertativo-argumentativos em prosa: o que se percebe em dez anos de realização do Enem? In: SILVA, L. R.; FREITAG, R. M. K. (Org.). Linguagem, interação e sociedade: diálogos sobre o Enem. CCTA: João Pessoa, 2015. p. 3350 .

AZEVEDO, I. C. M. Capacidades argumentativas de professores e estudantes da educação básica em discussão. In: Piris, Eduardo L.; Olímpio-Ferreira, Moisés (orgs.) Discurso e Argumentação em múltiplos enfoques. Coimbra: Grácio Editor, 2016. p. 167-190.

AZEVEDO, I. C. M.; FREITAG, R. M. K. Registros de práticas pedagógicas. O potencial do caderno pedagógico e do módulo didático. São Paulo: Pontes Editores, 2020.

BRASIL. Secretaria de Educação Básica. Base Nacional Comum Curricular. Brasília: MEC, 2018.

BRASIL. Ministério da Educação. Secretaria de Educação Fundamental. Parâmetros Curriculares Nacionais: língua portuguesa (1ª a ${ }^{\mathrm{a}}$ séries). Brasília: MEC, 1998a.

BRASIL. Ministério da Educação. Secretaria de Educação Fundamental. Parâmetros Curriculares Nacionais: terceiro e quarto ciclos do ensino fundamental: língua portuguesa Brasília: MEC/SEF, 1998b.

BRASIL. Ministério da Educação. Secretaria da Educação Média e Tecnológica. $P C N+$ : Ensino Médio - Orientações Educacionais Complementares aos Parâmetros Curriculares Nacionais. Linguagens, códigos e suas tecnologias. Brasília: MEC, 2002.

BRU, M. Les variations didactiques dans l'organisation des situations d'apprentissage. Toulouse: EUS, 1991.

DOLZ, J. Escribir textos argumentativos para mejorar su comprensión. Comunicación, Lenguaje y Educación, v. 25, p. 65-77, 1995.

FREIRE, P. Pedagogia da autonomia. Saberes necessários à prática educativa. 28. ed. São Paulo, 1996.

GRÁCIO, R. A. Para uma teoria geral da argumentação: questões teóricas e aplicações didácticas, 2010. 446 f. Tese (Doutoramento em Ciências da Comunicação), Instituto de Ciências Sociais, Universidade do Minho, 2010.

KLEIMAN, A. Abordagens da leitura. SCRIPTA, Belo Horizonte, v. 7, n. 14, p. 13-22, $1^{\circ}$ sem. 2004.

KOCH, I. V.; ELIAS, V. M. Escrever e argumentar. São Paulo: Editora Contexto, 2017.

LEFFA, V. J. Perspectivas no estudo da leitura; Texto, leitor e interação social. In: LEFFA, V. J.; PEREIRA, A. E. (orgs.) O ensino da leitura e produção textual. Alternativas de renovação. Pelotas: Educat, 1999. p. 13-37.

LIMA, S. F. A.; PIRIS, E. L. A ARGUMENTAÇÃO NO ENEM: Análise de Uma Redação Nota Mil. Mediação, Pires do Rio/GO, v. 12, n. 2, p. 217-231, jul.-dez. 2017. 
MONTE, N. S. A identificação da contra-argumentação na leitura de gêneros jornalísticos: uma experiência com estudantes do ensino fundamental. 2020. 131f. Dissertação (Mestrado Profissional em Letras) - Universidade Federal de Sergipe, São Cristóvão, SE, 2020. Disponível em: http://ri.ufs.br/jspui/handle/riufs/13620. Acesso em: 30 abr. 2021.

MOORE, M. Teoria da Distância Transacional. Revista Brasileira de Aprendizagem Aberta e a Distância, São Paulo, p. 1-14, ago. 2002.

MUÑOZ, N.; MUSCI, M. Manual de lectura y escritura argumentativas: aproximaciones teóricas y actividades prácticas. Río Gallegos: Universidad Nacional de la Patagonia Austral, 2013.

NEWELL, G. E.; BEACH, R.; SMITH, J.; Van Der HEIDE, J. Teaching and Learning Argumentative Reading and Writing: A Review of Research. Reading Research Quarterly, v. 3, n. 46, p. 273-304, 2011.

PAULIUKONIS, M. A. L. Conectores de oposição: reflexões e propostas para o ensino. Gragoatá, Niterói, n. 36, p. 28-42, 2014.

PERFETTI, Ch. A.; LANDI, N.; OAKHILL, J. A aquisição da habilidade de compreensão da leitura. In: SNOWLING, M. J.; HULME, Ch. A ciência da leitura. Trad. Ronaldo Cataldo Costa. Porto Alegre: Penso, 2013. p. 245-265.

PERRENOUD, Ph. Pedagogia diferenciada. Das intenções à ação. Porto Alegre: Artmed, 2000 .

PLANTIN, Ch. A argumentação - História, teorias, perspectivas. Trad. Marcos Marcionilo. São Paulo: Parábola Editorial, 2008a.

PLANTIN, Ch. A argumentação biface. In: LARA, G. M. P.; MACHADO, I. L.; EMEDIATO, W. Análises do discurso hoje. v. 2. Rio de Janeiro: Nova Fronteira, 2008b. p. 13-26.

PLANTIN, Ch. Análise e crítica do discurso argumentativo. EID\&A - Revista Eletrônica de Estudos Integrados em Discurso e Argumentação, Ilhéus, p. 229 - 263, 2011.

PLANTIN, Ch. "Não se trata de convencer, mas de conviver": a era pós-persuasão. Tradução de Weslin de Jesus Santos Castro e Eduardo Lopes Piris. EID\&A - Revista Eletrônica de Estudos Integrados em Discurso e Argumentação, Ilhéus, n. 15, p. 244-269, 2018 [2011].

PLANTIN, Ch.; MUÑOZ, N. I. El hacer argumentativo. Buenos Aires: Biblos, 2011.

REIS, L. R. O desenvolvimento da escrita argumentativa por estudantes do $9^{\circ}$ ano do ensino fundamental a partir da produção de gêneros jornalísticos. 2020. 153f. Dissertação (Mestrado Profissional em Letras) - Universidade Federal de Sergipe, São Cristóvão, SE, 2020. Disponível em: http://ri.ufs.br/ispui/handle/riufs/13619. Acesso em: 30 abr. 2021.

REZNITSKAYA, A.; ANDERSON, R. C.; McNURLEN, B.; NGUYEN-JAHIEL, K.; ARCHODIDOU, A.; KIM, S-Y. Influence of Oral Discussion on Written Argument. Discourse Processes, v. 32, n. 2-3, p. 155-175, 2001. DOI: http://doi.org/10.1080/0163853X.2001.9651596.

REZNITSKAYA, A., KUOB, L-J.; CLARKC, A.-M.; MILLERD, B.; JADALLAHD, M.; ANDERSON, R. C.; NGUYEN-JAHIE, K. Collaborative reasoning: a dialogic approach to group discussions Cambridge Journal of Education, v. 39, n. 1, p. 29-48, mar. 2009. 
ROSENBLATT, L. The transactional theory of reading and writing. In: RUDDELL, R. B.; RUDDELL, M. R. SINGER, H. (orgs), Theoretical models and processes of reading, 6. ed. Newark, DE: International Reading Association, 1994. p. 923-956.

SOUZA, M. M. S.; PIRIS, E. L. Reflexões acerca da proposta de ensino de argumentação em um livro didático de português aprovado pelo PNLD/2017. EID\&A-Revista Eletrônica de Estudos Integrados em Discurso e Argumentação, Ilhéus, n. 15, p. 175-195, jan./jun. 2018.

TOULMIN, S. E. Os usos do argumento. Trad. de Reinaldo Guarany. 2. ed. São Paulo: Martins Fontes, 2006 [1958].

VIDON, L. N. A prática escolar de ensino de gêneros do discurso argumentativo: pedagogia da dessubjetivação. Estudos Linguísticos, São Paulo, v. 42, n. 2, p. 743-755, mai./ago. 2013.

VIDON, L. N. A permanência da dissertação escolar nos exames vestibulares: o caso do Enem. In: AZEVEDO, I. C. M.; PIRIS, E. L. (org.). Discurso e Argumentação: fotografias interdisciplinares. v. 2. Coimbra: Grácio Editor, 2018. p. 31-44.

Recebido: 30/04/2021.

Aprovado: 01/07/2021. 